ISSN 1112-9867

http://www.jfas.info

\title{
EFFECTS OF WINDOW POSITION ON NATURAL CROSS VENTILATION IN VERNACULAR ARCHITECTURE OF MAZANDARAN (CASE STUDY: SARI)
}

\author{
S. Z. Galogahi ${ }^{1, *}$, M. Majidaee ${ }^{2}$, H. M. Beheshti ${ }^{3}$ and M. Alishah ${ }^{4}$ \\ ${ }^{1}$ Instructor of Sama technical and vocational college, Islamic Azad University, Sari \\ Branch, Sari, Iran \\ ${ }^{2}$ Department of architecture, Qazvin University of Science and Research \\ ${ }^{3}$ Department of architecture, Sari University of Science and Research \\ ${ }^{4}$ Department of architecture, Sari University of Science and Research
}

Published online: 11 June 2016

\begin{abstract}
Among the most effective architectures is vernacular architecture of Mazandaran whose incorporation in nature is so delicate that appears to be an essential part of it. Paying more attention to vernacular architecture and promoting it can be helpful in reducing energy consumption. Increasing use of fossil fuels in heating and cooling systems of buildings that come with excessive costs can result from inattention to vernacular architecture principles. However taking them into consideration can be an effective solution for reducing energy consumption. This research aimed to study the effects of window position on natural cross ventilation in Vernacular architecture of Mazandaran applying Descriptive - analytical approach. For this reason, a number of vernacular buildings, located in Sari, were studied regarding numbers and sizes of bilateral opening and its function in ventilation. Variables in this research were tested using SPSS and Regression correlation coefficient; additionally, all 3 formulas suggested in the results were evaluated to achieve an optimal model.
\end{abstract}

Author Correspondence, e-mail: s_zakiann@yahoo.com

doi: http://dx.doi.org/10.4314/jfas.8vi2s.68 
In this study, for a desirable ventilator, for every percent added to the room area, the windows showed a 0.87 percent increase in size, and for every additional story, the optimal ventilation grew 30 percent. On the other hand, in high-rise apartments, the protrusion contribution in ventilation system was highlighted. This research study aims to clarify the principles of proper ventilation in vernacular architecture which have long been forgotten.

Keywords: natural ventilation; window; vernacular architecture; temperate and wet climate.

\section{INTRODUCTION}

Today, energy saving and sustainable architecture are common international issues, so that reducing fossil energy consumption and coexisting with natural and climatic conditions are among the most architectural strategies. Environmental problems of air caused by indiscriminate use of natural resources have made architects use regional vernacular patterns and approaches in their designs (Salehi Imeni, 2013). However post-industrial progresses in technology and easy access to fossil fuels have caused fundamental changes in architecture among which we can refer to forgotten vernacular architectural patterns that once used to be created for more adaptability with climate. In the modern world, fossil energy is being used increasingly and people believe that without these sources of energy life is impossible. However, an overview of vernacular architecture demonstrates that in retrospect, architecture used to be incorporated in nature and this along with using renewable energy and constructing buildings with low energy consumption proves that it is feasible to live the most comfortable life without fossil fuels ( Qanbari and Sharif Qajeh Pasha, 2013). Yet according to the fact that energy resources are among human's basic needs, and also human has always wished for an infinite resource; wind as an infinite energy resource has always been center of human's attention. Now due to economic justifications and easy use of wind energy compared with other resources, it seems necessary to consider it as the main factor in buildings ventilation ( Mahmoodi and PurMusa,2010:147). Due to excessive growth of urbanization that has led to irresponsible consumption of energy ( Tanhaiyan and Kazemi, 2012) and huge cost of energy consumption during the recent decades, architects' main concern has been providing building with climatic comfort according to regional climatic conditions. While in vernacular Iranian houses, without any excessive cost and adding unnecessary complexity, architects were able to meet the residents' needs by developing intelligent designs and recognizing construction materials and elements besides taking into consideration the regional climatic issues (Puresmael, 2010). Today, natural ventilation, which creates natural air currents, can be one 
of the best and most economical alternatives to use energy optimally in buildings. Ventilation has been an inseparable part of vernacular architecture, however due to building density and modern architecture, today optimal using of wind energy is not considered as an internal ventilation factor anymore. Though, regarding high humidity of moderate and wet climate required for creating natural draft, natural ventilation can be helpful in buildings (Mahmoodi and Purmusa, 2010: 147). In this study, by evaluating opening surface in natural cross ventilation that creates natural draft inside the building and by considering the ratio of opening to windward surface and the building position, and also by deciding on number and size of openings set across each other we aim to recommend solutions for optimal use of natural ventilation in buildings, then according to results achieved we can find strategic patterns for building designs and we can access environment-oriented architecture.

\section{STATEMENT OF THE PROBLEM}

Today, with the development of technology and the importance of sustainable development and constructions in accordance with the vernacular architecture in line with efficient use of natural resources is of paramount importance. Understanding climatic conditions in every region is a main factor for peace and well-being of the users of buildings in that area because architecture and climate communication have a direct impact on each other. Vernacular architecture of this region from materials to the whole structure of construction is remarkably influenced by the surrounding environment and are the least harmful to it; moreover, reducing energy consumption using local materials causes environmental sustainability and durability of buildings (Qanbari and Tilmi, 2013). But over time and with the expansion of cities, the maximum number of housing units in one piece is built without considering the climatic conditions of the area in order to save land which in fact has caused problems for surface textures, streets and even inside buildings; additionally, fair wind that allowed optimal natural ventilation in buildings now changes direction due to the buildings erected with inappropriate angle and reduction of windows surfaces (it is a function of shapes and sizes of obstacles). This shift can cause discomfort rather than comfort if reaches a narrow space from an open space because its speed and intensity increases (Tahbaz, 2011). Buildings which were built in the past, produced an outstanding performance against unfavorable environmental factors due to following climatic principles and could naturally protected people against cold and hot weather. However, on the other hand, modern housing which is patterned on Western models are designed without any regard to regional issues and climate and thus has resulted in the conversion of houses into hostels and lack of comfort and a sense of identity crisis (Ahamdi et 
al, 2013). The most fundamental problem of ventilation in modern buildings is that people obey the common interest of their time. They making the windows integrated, remove the windows facing due to the neighborhood issues and remove terraces (passageway); today many residents remove their terraces to expand their living room develop the view of their apartments. By removing the central space, they in fact eliminate the most important ventilation factor and therefore cause heat to increase during summer and cold during winter as a large amount of heat loss through windows. Then to fix the problem, although they use double-glazed windows, residents still feel side effects, so that reducing indoor humidity needs keeping or removing vapor through ventilation (Ji Young Kim-Tahyvn Kim, 2011). However this ventilation is impossible due to removed facing windows and terraces, as well as inattention to climatic principles. During recent years, construction with the aim of constructing rather than living has left no opportunity to focus on important issues such as taking advantage of natural conditions and building consistency with climatic conditions. Thus at a time when we are facing energy crisis more than ever, devoting more attention to enriching characteristics of vernacular architecture that can help save consumption besides protecting underground resources and reducing pollution is essential (Qanbari and Sharif Qajeh Pasha, 2013). The purpose of this paper is to identify and evaluate the impact of ventilation on construction and vernacular architecture of temperate zone where modified building practices and offering a good strategy for greater use of natural ventilation can improve the buildings status.

To what extent can we make buildings that are appropriate and effective with natural ventilation in the regional architecture?

To what extent the removal passageway (wide porch) is causing problems with ventilation of modern buildings?

To what extent has shrinking the number of windows caused problems in allowing natural draft created? 


\section{LITERATURE REVIEW}

Table 1. Summary of studies in the field (the role of natural cross ventilation window on the vernacular architecture of Mazandaran)

\begin{tabular}{|c|c|c|c|}
\hline & scholar & subject & results \\
\hline 1 & $\begin{array}{l}\text { Qanbari and } \\
\text { Tilmi, } 2013\end{array}$ & $\begin{array}{l}\text { Design solutions } \\
\text { in the areas with } \\
\text { temperate and wet } \\
\text { climate according } \\
\text { to principles of } \\
\text { sustainable } \\
\text { architecture }\end{array}$ & $\begin{array}{l}\text { The importance of climate influence on } \\
\text { architecture, makes conducting } \\
\text { comprehensive studies and research } \\
\text { necessary in this field, especially in our } \\
\text { country whose climate diversity is } \\
\text { evident. Today, with the development of } \\
\text { technology, it is essential to consider } \\
\text { sustainable development and keep } \\
\text { construction in accordance with the } \\
\text { principles of climate. }\end{array}$ \\
\hline 2 & $\begin{array}{l}\text { Qanbari and } \\
\text { Sharif } \\
\text { Qajeh } \\
\text { Pasha, } 2013\end{array}$ & $\begin{array}{l}\text { The use of } \\
\text { vernacular } \\
\text { architecture in the } \\
\text { design of } \\
\text { residential } \\
\text { buildings of Gilan }\end{array}$ & $\begin{array}{l}\text { Technology growth after the Industrial } \\
\text { Revolution, followed by easier access to } \\
\text { fossil fuels has created a fundamental } \\
\text { shift in architecture to forget the most } \\
\text { important architectural patterns that } \\
\text { once emerged to adapt to the climate. In } \\
\text { the modern world people believe that } \\
\text { life is impossible without this energy, } \\
\text { but the course of traditional architecture } \\
\text { reflects the idea that the architecture was } \\
\text { always to integrate with nature }\end{array}$ \\
\hline 3 & $\begin{array}{l}\text { Ahmadi et } \\
\text { al, } 2013\end{array}$ & $\begin{array}{l}\text { adapting } \\
\text { residential home } \\
\text { design } \\
\text { vernacular } \\
\text { architecture and } \\
\text { climate }\end{array}$ & $\begin{array}{l}\text { Buildings that were built in the past } \\
\text { could produce outstanding performance } \\
\text { against adverse atmospheric factors due } \\
\text { to climatic principles and naturally } \\
\text { protected human against cold and hot } \\
\text { weather. }\end{array}$ \\
\hline 4 & MirMosavi & Climate comfort & With rising the cost of energy in recent \\
\hline
\end{tabular}




\begin{tabular}{|c|c|c|c|}
\hline & $\begin{array}{l}\text { and Shafie, } \\
2011\end{array}$ & $\begin{array}{l}\text { in designing } \\
\text { climate-harmonic } \\
\text { buildings }\end{array}$ & $\begin{array}{l}\text { decades has caused architects to concern } \\
\text { the most about climate comfort in } \\
\text { buildings according to regional climatic } \\
\text { conditions }\end{array}$ \\
\hline 5 & $\begin{array}{l}\text { PurEsmaeel, } \\
2010\end{array}$ & $\begin{array}{l}\text { The principles of } \\
\text { design and } \\
\text { construction } \\
\text { elements of } \\
\text { climate in Iranian } \\
\text { homes }\end{array}$ & $\begin{array}{l}\text { Despite the use of modern technology } \\
\text { and the cost of the construction of } \\
\text { houses, it can be seen that we haven't } \\
\text { been able to provide comfort as much as } \\
\text { we should. It is a result of the identity } \\
\text { crisis in current architecture and blind } \\
\text { imitation of Western architecture }\end{array}$ \\
\hline 6 & $\begin{array}{l}\text { Tanhaiyan } \\
\text { and } \\
\text { Kazemi, } \\
2012\end{array}$ & $\begin{array}{l}\text { Climatic pattern in } \\
\text { warm and dry } \\
\text { regions and its } \\
\text { impact on } \\
\text { reducing energy } \\
\text { consumption }\end{array}$ & $\begin{array}{l}\text { Population growth has had catastrophic } \\
\text { effects on the Earth's natural habitat and } \\
\text { urban sprawl has led to irresponsible } \\
\text { consumption of energy. }\end{array}$ \\
\hline 7 & $\begin{array}{l}\text { Kalantari } \\
\text { and Etesam, } \\
2014\end{array}$ & $\begin{array}{l}\text { Offering design } \\
\text { solutions for } \\
\text { humid and } \\
\text { temperate climate } \\
\text { zones based on } \\
\text { vernacualr } \\
\text { architecture }\end{array}$ & $\begin{array}{l}\text { Analysis and understanding of the } \\
\text { architectural features of the local area } \\
\text { can provide us with useful information } \\
\text { for developing proper and optimal } \\
\text { designs. Iran, due to the different } \\
\text { climate zones, has great architecture } \\
\text { adapted to any climate and region. }\end{array}$ \\
\hline
\end{tabular}

(Source: the author, 2015)

\section{THEORETICAL FOUNDATIONS}

\subsection{Vernacular architecture characteristics}

Architecture known as vernacular architecture, as accepted, includes only architectural ideas, tools and thoughts of a special and shift that requires changing the culture, customs and, of course, climate (Qanbari and Sharif Qajeh Pasha 2013). Vernacular Architecture of Iran, unlike most modern buildings, is consistent with natural conditions and has harmonious relationship with its environment and in order to create an appropriate and sustainable 
environment it is incorporated in it so that not only prevents harm harms but improves it (Armaqan, 2009:20). This vernacular knowledge is based on experience and has tested over time and has adapted to the local culture and environment, and thus has acquired the necessary dynamism and efficiency. This knowledge is not limited to ethnic groups or residents of a rural area but belongs to all urban and rural and nomadic communities (IIRR, 1996:7), and it is a part of the national wealth of any nation that involves their beliefs, values, and local knowledge and is the result of centuries of trial and error in environment that often transmitted from generation to generation orally (Emadi, 1999:1).

\section{Texture}

If you are in the northern region enclosed spaces and drafts of air and the wind does not flow in the city all the spaces of moist air will accumulate and breathing and will be very onerous, that's why you should take advantage of the air flow (Qobadiyan, 2006:38). In temperate and humid, air flow is critical in natural ventilation and texture should have a distributive design, so that wind could direct heat away from the buildings (Tahbaz, 2011). following the distribution of scattered ownership of agricultural land, homes of this coastal area are scattered (AqebatBekheir and Moharami, 2010:77), and buildings in this area are made separately, with large fenced yard and open spaces around these spaces are often shorter than human height (to remove obstacles in the path of air flow). The reason is to allow the air flow to pass through buildings and take stagnant humid air out into the living spaces (Qobadiyan, 2006: 40). Streets are fairly wide and flat and generally in coastal areas they overlook the sea. (Due to sea breeze flowing to the beach)(Kasmaee,2005: 122).

\section{Outward-orients}

Mazandaran vernacular architecture is combined with nature in a way that can be called "nature-oriented". An architecture known as outward-oriented architecture due to its adaptation to environmental conditions and climate (Shahroodi and Rezaee:37). Formation of outward-oriented buildings in this area is primarily due to its use of air drafts, moisture and make maximum use of proper perspective and monitoring the yard's range (Gorji Mahlbani, 2010: 142). Among its feature are a visual and physical relationship with the outer space of the house, having no yard, and spreading at a height that all can be seen in vernacular architecture. Note that buildings are located in green vegetation (QolamiTavani and MolaeeTavana, 2010: 2).

\section{Building orientation}


Building orientation is important because it can increase or decrease the effect of ventilation on the building. The more expanded the windward side of the building is, the more the natural draft will be received, if air mobility and air flow exist in the right place. (Tahbaz, 2011) Use of free forms that have elongated through east-west axis is effective in vernacular architecture of temperate zone. (Georgian Mahlabani, 2010) In general, plans are open wide, long, and narrow. In order to take advantage of wind ventilation inside the room, the placement of buildings is set according to the direction of the sea breeze. (Kasmaee, 2003: 87).

\section{Passageway}

Spaces with two rows of columns in front of the Hall are called passageway. As well as to protect the wall of a "passageway" expands like a porch around the perimeter of the building. Roof is expanded to cover the whole passageway. (Gor Mahlabani, 2010 : 138) in this regard, creating the passageway and the cover over it, all the walls will be protected and there is a good atmosphere in the shade, and air flow could easily pass (Qobadiyan, $2006: 42$ ).

\section{Crawl space}

Architecture blend with the earth and nature in Mazandaran, is associated with both compliance with it and its efficiency (Kolbadi Nejad, 84). Because of the humidity and shallow ground water, the ground floor of the building is built above the natural ground so that the floor is away from moisture and it allows enjoying the wind that has greater speed at height (Qobadiyan, 2006:42).

\section{Porch}

The most basic comfort for those living in humid and rainy areas is that in urban areas, wind and bilateral drafts air inside the buildings, when raining, wide covered terraces are used to protect against rain. In summer it also reduces the sun depth of penetration which is almost vertical, while in winter when sun has a non-perpendicular position; penetration depth could be greater (Kasmaee, 2005: 83).

\section{Materials}

Due to high humidity and rainfall, especially in rural areas most buildings are made apart and away from each other, and due to the abundance of wood in this area, the buildings are mainly built of wood or light materials and then covered by steep rooftops (Zomorshidi, 2005).

\section{Cotam (a Mazandarani term)}

It is a porch or summer building that in Mazandarani accent refered to as Nfar. The heat and high humidity in the summer causes sultry weather in the region. This semi-open space that is 
open on all four sides and is above the ground can be effective due to the light breeze and draft created in many ways, to achieve climatic comfort (Gorji Mahlabani, 1389: 130).

\subsection{Climatic features of Mazandaran}

Mazandaran province is located with an area of over 44552 square kilometers between 35 degrees and 47 minutes north latitude and 50 degrees 38 degrees 5 minutes and 34 minutes to 56 degrees and 14 minutes east of the Greenwich meridian (Faqih, 2003: 30). Caspian Sea coast with a temperate climate and abundant rainfall is a moderate region. This area that is surrounded by a strip of Alborz Mountains and the Caspian Sea comprises low plains in which moisture reduces by its development toward the East (Kasmaee, 2003: 83). Moderate temperature, high humidity and abundant rainfall are among the most important features of the area. The average maximum temperature in the hottest month of the year (August) is between 25.8 to 36.6 and the average minimum temperature in the coldest month (January) is between 5.4 to 8.6 degrees Celsius. In all parts of the region, rainfall in all months of the year has been significant and most stations measured the rainfall more than $500 \mathrm{~mm}$ (Kasmaee, 2008: 23). The building typology involves invisible boundaries and limits, regarding family needs, privacy, and social relations. The ruling climatic conditions impose its own making style. As a result, the main factor contributing to the formation of this architecture is climate (Diba, 1993: 13).

\subsection{Natural ventilation}

Natural ventilation of buildings energy storage system is necessary for physical comfort of residents in which indoor air is constantly being exchanged with fresh air through openings, however lack of this ventilation causes pollution, suffocation, and discomfort resulting from odor and heat (Mayo - Lyn,2012). Natural ventilation is conducted through exchange process of indoor air with the outside fresh air (cooling atmosphere) without using mechanical devices which saves on the consumption of fossil fuels. In this process, indoor heavy air is replaced with fresh light air. Though the impact of unfavorable winds and controlling it should be considered (Tahbaz, 2011). Today, the use of natural draft is more complicated than before and embedding multiple windows by imitation does not suffice (Tahbaz, 2011). If location, position, design, ambient conditions and the environment is satisfactory, efficient natural ventilation systems can help achieve this goal. According to Orme, air-conditioning systems 
in buildings and residential services includes $48.26 \%$ of total annual energy consumption. (Mayo_Lyn, 2012).

\subsection{Window}

Energy consumption in our country is higher than the international standard whose main reason can be external walls (window) that has a huge impact on the energy consumption of thermal welfare (Ebrahipur and Kari , 2011: 77). Window is one of the factors that significantly contribute to shaping the appearance of residential buildings and, as a result, transferring architectural and climatic features, and if it involves the building-related environmental and cultural characteristics, it can express the architectural identity of its own location and climate. The properties are seen in the window of traditional structures (case studies selected in this study). However modern developments and infinite freedom in the form of building elements, has created disorder and sometimes has formed uniform windows that are unrelated to the culture. This has diminished the functional role of windows. It should be noted that the use of windows in houses in Iran with different climates, shows that contrary to the common scientific views in which only climatic factors decide on size and diversity windows, is more affected by Iranian culture and home spaces (Parsa, 2011: 75).

\section{RESEARCH METHODOLOGY}

This article is based on research conducted during a university project and according to the nature of the subject and the purposes predicted; it is a cross-sectional applied research. Since in this study, questionnaires and interviews were used to collect the required information, then from another point of view, this study could be considered as Survey research. Information required for this study, was collected through documents (library) and surveys. This study examines the role of ventilation in the window of the three samples of vernacular building located in moderate and humid regions of Sari (a city in Mazandaran, Iran) and the information variables assessed in this study using SPSS software and regression correlation coefficient tests.

\section{HYPOTHESIS AND DISCUSSION}

\subsection{Study model}

Study model was selected from vernacular buildings of moderate and wet regions of Sari that has several openings (three openings) on the front or rear wall and allows air smoothly into the building to create comfort. Air movement through openings that are set across each other 
can create natural ventilation that is influenced by the number and the size of openings that's why we can say that the position of the window according to the size of the aperture, incoming air speed, direction and temperature difference are playing an important role in flow of air and optimal conditioning. In this context, three samples were studied:

Case 1: bilateral cross ventilation with seven holes in the windward wall (Figure 1: Home of Fazelis).

Case 2: bilateral cross ventilation with five holes in the windward wall (Figure 2: Home of Klbady).

Case 3: bilateral cross ventilation with three holes in the windward wall (Figure 3: Home of Ramedani)
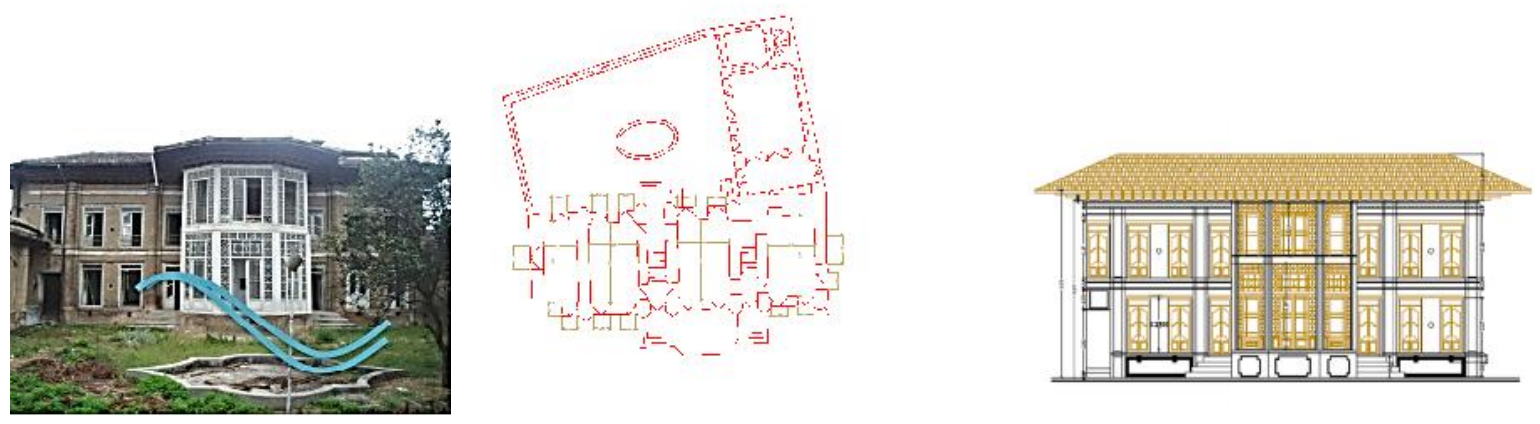

Fig.1. Home of Fazelis
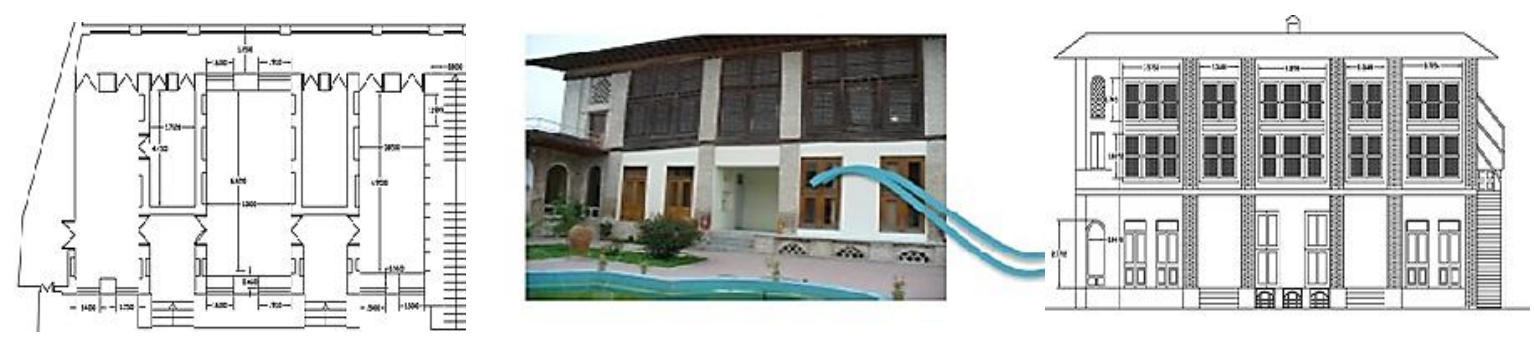

Fig.2. Home of Klbady
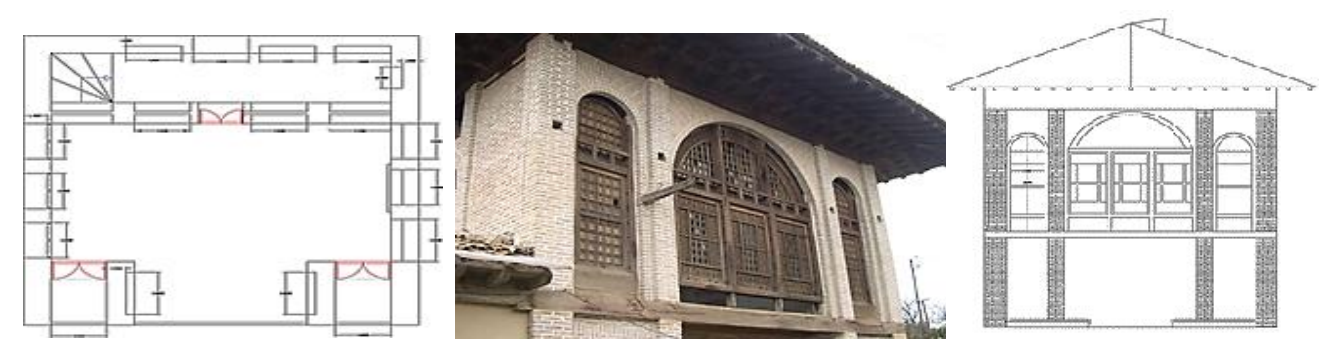

Fig.3. Home of Ramedani 


\subsection{Model making}

Since old houses, without cooling and heating systems, could bring comfort to residents, so for construction of model it is assumed that the desired ventilation, openings, and windows correlate.Thus good ventilation is considered as a dependent parameter $\mathrm{T}$. The parameters that are effective in ventilation are defined as below

1-parameter A: room area

2. Parameter S: window surface

3. Parameter M: building height

4. Parameter F: protrusion

5: Parameter T: desirable ventilation

6. Parameter C: independent parameter

According to the dimensions of the window openings in home of Fazli, Klbady, and Rmdany, the following relation is obtained in terms of ratio between room area and opening surfaces. For every square meter of room area, an opening with 0.6 to 0.75 square meter surface is built; this ratio increases about 0.05 for every floor from the first floor to the upper floors. In the first step of this model, according to data obtained, correlation coefficient needs to be investigated between any two independent variables. Therefore, the correlation of the model is obtained through tests. In this regard three linear, logarithmic, and exponential models are assumed that after model analysis, the optimum model is selected based on $T \approx 100$.

(1) Linear model

$T=c_{1} \times(A)+c_{2} \times(S)+c_{3} \times(M)+c_{4} \times(F)$

(2) Logarithmic model

$\log T=c_{1} \times \log (A)+c_{2} \times \log (S)+c_{3} \times \log (M)+c_{4} \times \log (F)$

(3) Exponential model

$T=\exp \left(c_{1} \times A\right)+\left(c_{2} \times S\right)+\left(c_{3} \times M\right)+\left(c_{4} \times F\right)$

\subsection{Data analysis}


Steps taken to construct a model in order to achieve a desirable and efficient model mentioned in the previous section summarized as follows: In the first stage, all effective qualitative and quantitative variables were identified and selected from valid resources and through evaluation to determine the amount of optimal conditioning. Next, the correlation between variables was examined in order to remove the same variables. After identifying the variables most useful to construct a model, the general form of the model was selected that has the highest correlation. This process is based on stages and trial and error to achieve optimum results. The right model is selected based on engineering judgment. Thus, according to the process described, the most appropriate model is obtained according to the specified general form. In general, the data used in this study came to 21 that is provided through a map of the buildings in question. Also in this study, statistical models were used as linear, logarithmic, and exponential functions whose mathematical form is shown.

\section{STAGE}

\subsection{Correlation between different variables and the dependent variable (optimal ventilation)}

Null hypothesis: there is no correlation between the variables

Alternative hypothesis: There is a correlation between the variables

By examining correlations between different variables and optimal ventilation, parameters in the ventilation model are optimal.

Table 2. Correlation between different variables and optimal ventilation

\begin{tabular}{|c|c|c|c|c|}
\hline variable 1 & Variable 2 & $\begin{array}{l}\text { Correlation } \\
\text { coefficient value }\end{array}$ & $\begin{array}{l}\text { Significance } \\
\text { level }\end{array}$ & result \\
\hline Room area & $\begin{array}{l}\text { Optimal } \\
\text { ventilation }\end{array}$ & 0.336 & 0.000 & $\begin{array}{l}\text { Entered } \\
\text { model }\end{array}$ \\
\hline Window surface & $\begin{array}{l}\text { Optimal } \\
\text { ventilation }\end{array}$ & 0.226 & 0.000 & $\begin{array}{l}\text { Entered } \\
\text { model }\end{array}$ \\
\hline Building height & $\begin{array}{l}\text { Optimal } \\
\text { ventilation }\end{array}$ & 0.686 & 0.000 & $\begin{array}{l}\text { Entered } \\
\text { model }\end{array}$ \\
\hline Protrusions & $\begin{array}{l}\text { Optimal } \\
\text { ventilation }\end{array}$ & 0.356 & 0.356 & $\begin{array}{l}\text { Entered } \\
\text { model }\end{array}$ \\
\hline
\end{tabular}

(Source: the author, 2015) 


\subsection{Correlation between different variables for the final entry in the ventilation model}

Null hypothesis: there is no correlation between the variables

Alternative hypothesis: There is a correlation between the variables

Table 3. Correlation between different variables

\begin{tabular}{llllll}
\hline variable 1 & Variable 2 & $\begin{array}{l}\text { Correlation } \\
\text { coefficient value }\end{array}$ & $\begin{array}{l}\text { Significance } \\
\text { level }\end{array}$ & result \\
\hline $\begin{array}{l}\text { Area of each } \\
\text { room }\end{array}$ & Building height & 0.0167 & 0.072 & No correlation \\
\hline $\begin{array}{l}\text { Area of each } \\
\text { room }\end{array}$ & Window surface & 0.173 & 0.143 & No correlation \\
\hline $\begin{array}{l}\text { Area of each } \\
\text { room }\end{array}$ & Protrusions & 0.094 & 0.085 & No correlation \\
\hline $\begin{array}{l}\text { Building height } \\
\text { Building height }\end{array}$ & Protrusions & 0.006 & & 0.651 & No correlation \\
\hline Window surface & Protrusions & 0.132 & 0.192 & No correlation \\
\hline
\end{tabular}

(Source: the author, 2015)

\subsection{Hypothesis testing}

This section examines the hypotheses testing through Pearson correlation and regression tests. In this test, the null hypothesis expresses no significant relationship between the two variables, while the alternative hypothesis expresses a significant relationship. If the significance level is less than 0.05 , the null hypothesis is rejected and with $95 \%$ confidence we can say that there is a significant correlation between the two variables. By analyzing the data in SPSS software, three models have been studied and the top model is introduced.

\subsection{Determining the regression equation to the optimal ventilation system}

In this part, statistics of the buildings owned by Klbady, Rmdany and Fazeli are used.

\section{Analysis of model 1:}

$T=c_{1} \times(A)+c_{2} \times(S)+c_{3} \times(M)+c_{4} \times(F)$ 
Table 4. Summary of regression model of area of the room, the protrusions, the height of buildings and the window surface on optimal ventilation

\begin{tabular}{lll}
\hline $\begin{array}{l}\text { Coefficient of } \\
\text { Determination }\left(\mathrm{R}^{2}\right)\end{array}$ & $\begin{array}{l}\text { Multiple } \\
\text { coefficient }\end{array}$ & correlation \\
\hline 0.598 & 0.773 & \\
\hline
\end{tabular}

(Source: the author, 2015)

The coefficient of determination is 0.598 . According to the above table as the coefficient of determination is low, the second model is examined.

\section{Analysis of model 2 (Algorithmic)}

$\log T=c_{1} \times \log (A)+c_{2} \times \log (S)+c_{3} \times \log (M)+c_{4} \times \log (F)$

Table 5. Summary of regression model of area of the room, the protrusions, the height of buildings and the window surface on optimal ventilation

\begin{tabular}{lll}
\hline $\begin{array}{l}\text { Coefficient of } \\
\text { Determination }\left(\mathrm{R}^{2}\right)\end{array}$ & $\begin{array}{l}\text { Multiple } \\
\text { coefficient }\end{array}$ & correlation \\
\hline 0.773 & 0.706 &
\end{tabular}

(Source: the author, 2015)

\section{Analysis of model 3 (exponential)}

Exponential model

$$
T=\exp \left(c_{1} \times A\right)+\left(c_{2} \times S\right)+\left(c_{3} \times M\right)+\left(c_{4} \times F\right)
$$

Table 6. Summary of regression model of area of the room, the protrusions, the height of buildings and the window surface on optimal ventilation

\begin{tabular}{cc}
\hline $\begin{array}{c}\text { Coefficient of Determination } \\
\left(\mathrm{R}^{2}\right)\end{array}$ & $\begin{array}{c}\text { Multiple correlation } \\
\text { coefficient }\end{array}$ \\
\hline 0.348 & 0.125
\end{tabular}

(Source: the author, 2015) 
Table 7. Summary of ANOVA table

\begin{tabular}{cc}
\hline F-statistics & Significance level \\
\hline 195.213 & 0.755 \\
\hline
\end{tabular}

(Source: the author, 2015)

Based on the table shown below, since there is a significance level of ANOVA is greater than 0.05 it can be said with $95 \%$ confidence that the selected model is not proper.

Table 8. An overview of models

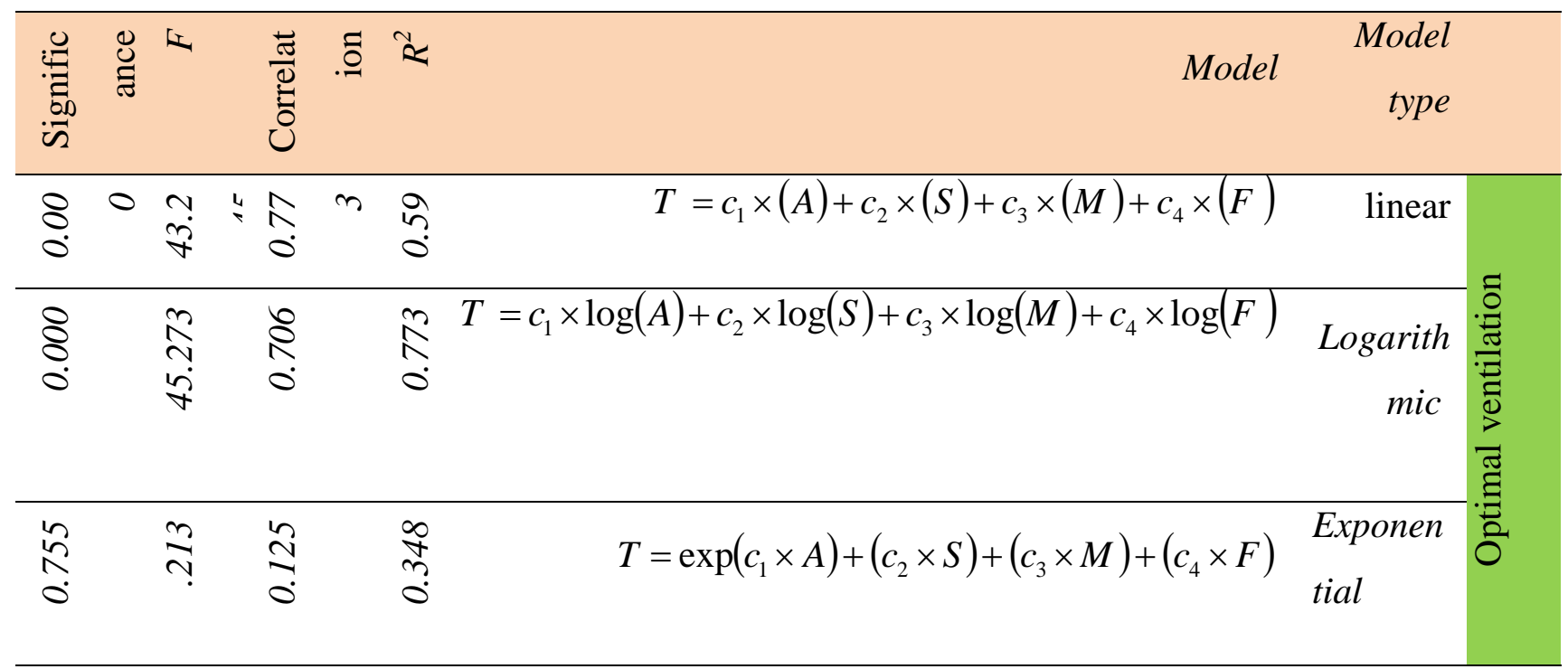

(Source: the author, 2015)

Given that coefficient of determination is obtained 0.773 for the second model (logarithmic) this model is introduced as the superior model and thus all results will be presented on a logarithmic model.

Table 9. Summary of ANOVA table

\begin{tabular}{|c|c|}
\hline F-statistics & Significance level \\
\hline 45.258 & 0.000 \\
\hline
\end{tabular}

(Source: the author, 2015)

According to Table 8 as the significance level is less than 0.05 , it can be said with $95 \%$ confidence that the model which is an algorithmic model is good and assumption of zero coefficients is rejected.

\subsection{Regression Coefficients}


Table 10. Summary of regression model to estimate the optimal ventilation

\begin{tabular}{llllll}
\hline variables & $\begin{array}{l}\text { Significance } \\
\text { level }\end{array}$ & t-statistics & $\begin{array}{l}\text { Standardized } \\
\text { coefficient } \\
\text { beta }\end{array}$ & $\begin{array}{l}\text { Standard } \\
\text { deviation }\end{array}$ & $\begin{array}{l}\text { Beta } \\
\text { coefficient }\end{array}$ \\
\hline $\begin{array}{l}\text { Window } \\
\text { surface }\end{array}$ & 0.0000 & 43.543 & 0.478 & 0.215 & 145.356 \\
\hline Room area & 0.000 & 17.112 & 0.548 & 0.325 & 165.482 \\
\hline $\begin{array}{l}\text { Building } \\
\text { height }\end{array}$ & 0.000 & -25.927 & 0.125 & 0.126 & 259.147 \\
\hline Protrusions & 0.000 & -66.623 & 0.015 & 0.135 & 0.586 \\
\hline
\end{tabular}

(Source: the author, 2015)

The selected regression model is:

LOG ventilation $=0.478(\mathrm{LOG}$ window surface $)+0.548(\mathrm{LOG}$ room area $)+0.125(\mathrm{LOG}$ building height $)+0.015$ (LOG Protrusions)

\section{CONCLUSION}

Vernacular architecture of humid climate which includes a large part of lands located along south of Caspian sea has been neglected over time, and most traditional areas of the region have been destroyed. Because of the separation of local architecture and modern architecture, architects of these regions should study the climatic conditions in order to develop appropriate and useful ideas and provide solutions suited to the climate (Kalantari and Etesam, 2014). In this study, evaluating the role of windows in natural cross ventilation and obtained results, as well as study model which is number and size of windows under draft show that in cross ventilation, windows are input and output of the two-way ventilation, In this case, if the wind speed has a linear change, the volume of inflow into the windows, as well as ventilation velocity will have a linear change. Due to the optimized model (logarithmic model), the ratio of the area of the room and the window surface to other parameters is more in creating optimal ventilation. Building height and protrusions are next priorities. For a good ventilation system, for about of every percent of room area expansion, window surface shows about 0.87 percent growth and for every floor, optimal conditioning increases about 30 percent. Also in higher floors, the role of protrusions is highlighted. However it should be noted that at present, establishing vernacular architecture alone is not able to respond to the needs of our 
residents so by being inspired by the vernacular characteristics and mixing them with technology of the time, we can achieve better results.

\section{REFERENCES}

[1] Vahid A, Arefeh P, Talebi F. Adaptation of residential home design and architecture appropriate to the vernacular climate, the National Congress of architecture, urban planning and sustainable development of vernacular architecture with a focus on the sustainable city, 1932, Khavarn Institute, Mashhad.

[2] Pooresmaeel M. R. A study of design principles and structural elements at the Iranian climate (cold and mountainous), Regional Conference on Iranian house, Islamic Azad University of Gonbad, Gonbad-e Qabus, 1389.

[3] Tanhaeean, Vida, Kazemi, Mehrvash. Patterns in warm and dry climate and its impact on the reduction of energy consumption in designing, the first national conference ideas and new technologies in architecture, architects Tabriz Forum, 1391.

[4] Diba, Kamran and Shahryar Yaqini. Adapting perspective to climate, Journal of Architecture, Tehran, 1372, No. 24.

[5] Shahroudi, A, Rezaei, Bahram. Mazandaran vernacular architecture interaction with tourism, Journal of Civil Engineering, No. 24, pp. 37 -39.

[6] Salehi Emeni A. Sustainability and traditional building concepts of humid temperate regions of Iran, National Conference on architecture and urban development, Khavaran Institute, Mashhad, 1392.

[7] Qobadian, V. The Climate of traditional buildings, Tehran, Tehran University Press, 1385 .

[8] Ghanbari Tillmi Z. providing designing solutions in the areas with temperate and humid climate based on the principles of sustainable architecture (Case Study: South Bank of Caspian Sea), National Conference on sustainable architecture and urban development, Sazeh, Kavir, Bukan firms, 1392.

[9] Ghanbari Susan, Sharif Khajeh Pasha, Sepideh. Using vernacular architectur in design of residential buildings of Gilan, the first national conference of ideas and new technologies in architecture, architects Tabriz Forum, 1391.

[10]Faqih, T. From Tabarestan to Mazandaran, Journal of Ferdowsi, 1382, No. 5, pp. 28-30.

[11]Aqebatbekheir, Hamed and Moharemi Namin, S. Rural housing design (Case attitudes Caspian region), published by the Jahan-eJam-e jam, Tehran, 1389. 
[12]Emadi, Mohammad Hussain Abbasi, Esfandiar. Vernacular knowledge and development periodical, 1378.

[13]Qolami Tavani, Maryam and Molaee Tavana, H. Sustainability in stable settlements in the vernacular habitat of Caspian sea, the first conference on sustainable urban development, 1389.

[14]Tahbaz, M. Design of outdoor shade, Journal of Fine Arts, 31, 1390.

[15] Tahbaz, M. The impact of the steep rain on the building, Magazine Profile, 1374, No. 50, pp 35-43.

[16] Armaqan. The role of design in reducing energy consumption in buildings, Journal of Fine Arts, 1388, No. 129, p. 9.

[17] Kasmaee, M. Climate and Architecture, Isfahan, Khak publication, 1382.

[18]Kasmaee, M. Zoning and climatic design guidelines- temperate and humid climateGilan and Mazandaran provinces, Journal of Construction Engineering and Housing Sciences, 1387, No. 12, pp. 23-32.

[19]Kalantari, Fatima, Etesam, I. Providing climatic design solutions in the areas with temperate and humid climate based on vernacular architecture (Case Study: Farah Abad village), the second National Conference on Tabaristan art, Mazandaran University, Babolsar, 1393.

[20]Klbady Nejad, M. The land and the architecture of Mazandaran, Journal of Architecture and Culture, No. 33, pp. 82-85.

[21]Gorji, Mahlabani, Joseph, Daneshvar, Kimia. The impact of climate on the formation of traditional architecture elements in Gilan Province, the magazine of Aramn Shahr, 1389, No. 4, p. 137.

[22]Mir Mousavi, Seyed Hossein., Shafi'i, Shahab. Study of climatic comfort for building design compatible with the climate case study Tehran, National Congress on structures, road, architecture, Islamic Azad University of Chalus, 1390.

[23] Mahmoudi, Pourmusa, M. M. The potential of wind energy and its fundamental role in the air conditioning case study Rasht (Golsar area), Journal of Arman Shahr, 1389, No. 4, pp. 147.

[24]Ibrahim Pur, Abdul Salam, Mohammad work, B. A new way to design windows with respect to energy consumption", Journal of mechanical engineering lecturer, 1390, 11(1), 77. 
[25]Parsa, M. A. An Inquiry into the origins of architectural window pane in the Persian language and Iranian culture, Journal of rural housing environment, 1390, No. 134, p. 75. [26]m.z.i.bangalee, s.y.lina,j.j.miau. Wind driven natural ventelation through multiple windows of a building:a computational approach, Energ and buildings, 2012, 45, 317325.

[27]jiyoeng kim ,taeyeon kim,seung-bok leigh, window system with ventilation slit to prevent window surface condensation buildings, Energ and buildings, 2011, 43, 3120-3130.

[28]A manual IIRR. International Institute of Ruralreconsruction, printed in India, Recording and using indigenous knowledge, 1996.

\section{How to cite this article:}

Galogahi S. Z, Majidaee M, Beheshti H. M. and Alishah M. Effects of Window position on natural cross ventilation in vernacular architecture of Mazandaran (Case study: Sari). J. Fundam. Appl. Sci., 2016, 8(2S), 567-586. 